\title{
A unique case of recurrent fetal cystic hygroma: first fetus with an inherited heteromorphism of chromosome 1 (1qh+) and the second fetus with 69XXX triploidy
}

\author{
OANA SORINA TICA ${ }^{1,2)}$, CRISTINA GUG ${ }^{3)}$, ANDREI AdRIAN TICA ${ }^{2,4)}$, CRISTINA JANA BUSUIOC ${ }^{5,6)}$, \\ SHAHRAM AMIRI ${ }^{7)}$, IRINA TICA ${ }^{8,9)}$, GEORGE BICĂ BRĂILOIU ${ }^{4)}$, VLAD IUSTIN TICA ${ }^{10,11)}$ \\ 1) Department of Mother and Child, University of Medicine and Pharmacy of Craiova, Romania \\ 2) Department of Obstetrics and Gynecology, Emergency County Hospital, Craiova, Romania \\ ${ }^{3)}$ Department of Genetics, Victor Babeş University of Medicine and Pharmacy, Timişoara, Romania \\ 4) Department of Pharmacology, University of Medicine and Pharmacy of Craiova, Romania \\ 5) Department of Histology, University of Medicine and Pharmacy of Craiova, Romania \\ ${ }^{6}$ Department of Endocrinology, PanMed Medical Center, Craiova, Romania \\ 7)Department of Obstetrics and Gynecology, City Hospital of Turceni, Romania \\ ${ }^{8)}$ Department of Internal Medicine, Faculty of Medicine, Ovidius University of Constanta, Romania \\ 9) Department of Internal Medicine, University Regional Emergency Hospital, Constanta, Romania \\ ${ }^{10)}$ Department of Obstetrics and Gynecology, Faculty of Medicine, Ovidius University of Constanta, \\ Romania \\ ${ }^{11)}$ Department of Obstetrics and Gynecology, University Regional Emergency Hospital, Constanta, \\ Romania
}

\begin{abstract}
The authors report a unique recurrent septated cystic hygroma $(\mathrm{CH})$, on two successive pregnancies, at five years interval. The chromosome analysis of the first fetus showed an increase in length of heterochromatin on the long arm of chromosome 1 - 1qh+, a chromosomal polymorphism inherited from mother, 46XX,1qh+,14ps+,21ps+. The karyotype of the second $\mathrm{CH}$, with more severe ultrasound (US) imaging, showed a 69XXX triploidy. The patient took no risk and underwent each time a termination of pregnancy (TOP). The first karyotype is generally considered "normal", although there are few reports linking 1qh+ with low fertility, but this was not the case, the patient having, from a previous marriage, a healthy boy and two TOPs. So, this "particular", but "healthy" karyotype was not a cause for the first $\mathrm{CH}$. The second karyotype highlights a possible causality between the 69XXX triploidy, usually associated with partial hydatidiform mole, and a more severe septated $\mathrm{CH}$ in the last fetus. Neither the $\mathrm{CHs}$ ' appearance nor their recurrence seemed to be family linked, as the two $\mathrm{CHs}$ had distinct genetic profiles. We recommend that, once $\mathrm{CH}$ is diagnosed, a careful US examination is compulsory for the determination of subcutaneous edema, ascites, pleural and pericardial effusions and cardiac or renal abnormalities; an early genetic work-up is mandatory, by chorionic villus sampling or amniocentesis. However, a "healthy" karyotype does not exclude a severe form, as in our first case of $\mathrm{CH}$. Due to the very poor outcome of fetuses with $\mathrm{CH}$, the patient must be thoroughly informed about the short and the long-term fetal prognosis.
\end{abstract}

Keywords: cystic hygroma, karyotype, heterochromatin, inherited polymorphism, triploidy.

\section{Introduction}

Cystic hygromas (CHs) are cystic congenital malformations of the lymphatic system, more frequently situated posteriorly to the neck $[1,2]$, but they can occur in many other sites [3]. The outcome of the $\mathrm{CH}$ is very poor, often progresses to hydrops fetalis (HF) and cause fetal death [4]. This disease frequently associates chromosomal abnormalities, Turner's syndrome being the most common $[2,4]$. CHs are not, usually, inherited, although some studies showed familial recurrence, with "normal" karyotypes and raised the hypothesis of an autosomal recessive transmission of the disease [5-7]. Recurrence of $\mathrm{CHs}$ with different karyotypes is rarely observed, only few cases being presented until now $[8,9]$.

\section{Aim}

Here, we report an extremely rare case of recurrent $\mathrm{CH}$ with $\mathrm{HF}$, revealing unique karyotypes of the fetuses. A brief review of the literature is also presented.

\section{ㅁ Case presentation}

A 27-year-old woman gravida 3 and para 1 arrived for a routine visit at around seven weeks of amenorrhea. Ultrasound (US) scan showed a gestational sac $(18 \mathrm{~mm}$, corresponding to six weeks and four days of amenorrhea), with an embryo having cardiac activity [heart rate (HR) 163 beats per minute $(\mathrm{bpm})]$. The history, the clinical examination and the laboratory tests revealed no

This is an open-access article distributed under the terms of a Creative Commons Attribution-NonCommercial-ShareAlike 4.0 International Public License, which permits unrestricted use, adaptation, distribution and reproduction in any medium, non-commercially, provided the new creations are licensed under identical terms as the original work and the original work is properly cited. 
abnormalities. She had, with her first husband, a 4-yearold boy and, thereafter, two terminations of pregnancy (TOPs) on her request. The pregnancy presented here was the first obtained with the second, actual, husband.

She was advised to come back between 11 and 14 weeks of pregnancy for a first trimester screening.

The patient returned five weeks later, when US examination revealed a fetus with a crown-rump length
(CRL) of $5.09 \mathrm{~cm}$, corresponding to 11 weeks and six days of amenorrhea. The fetus presented a large septated thin-wall sac, situated predominately on the neck, mainly on the left side, with a nuchal translucency (NT) of $5.06 \mathrm{~mm}$ (Figure 1, A-C). The embryo also showed subcutaneous edema, especially on the anterior body wall, with a maximal thickness of $1.1 \mathrm{~mm}$ (Figure 1D), without any other effusions.
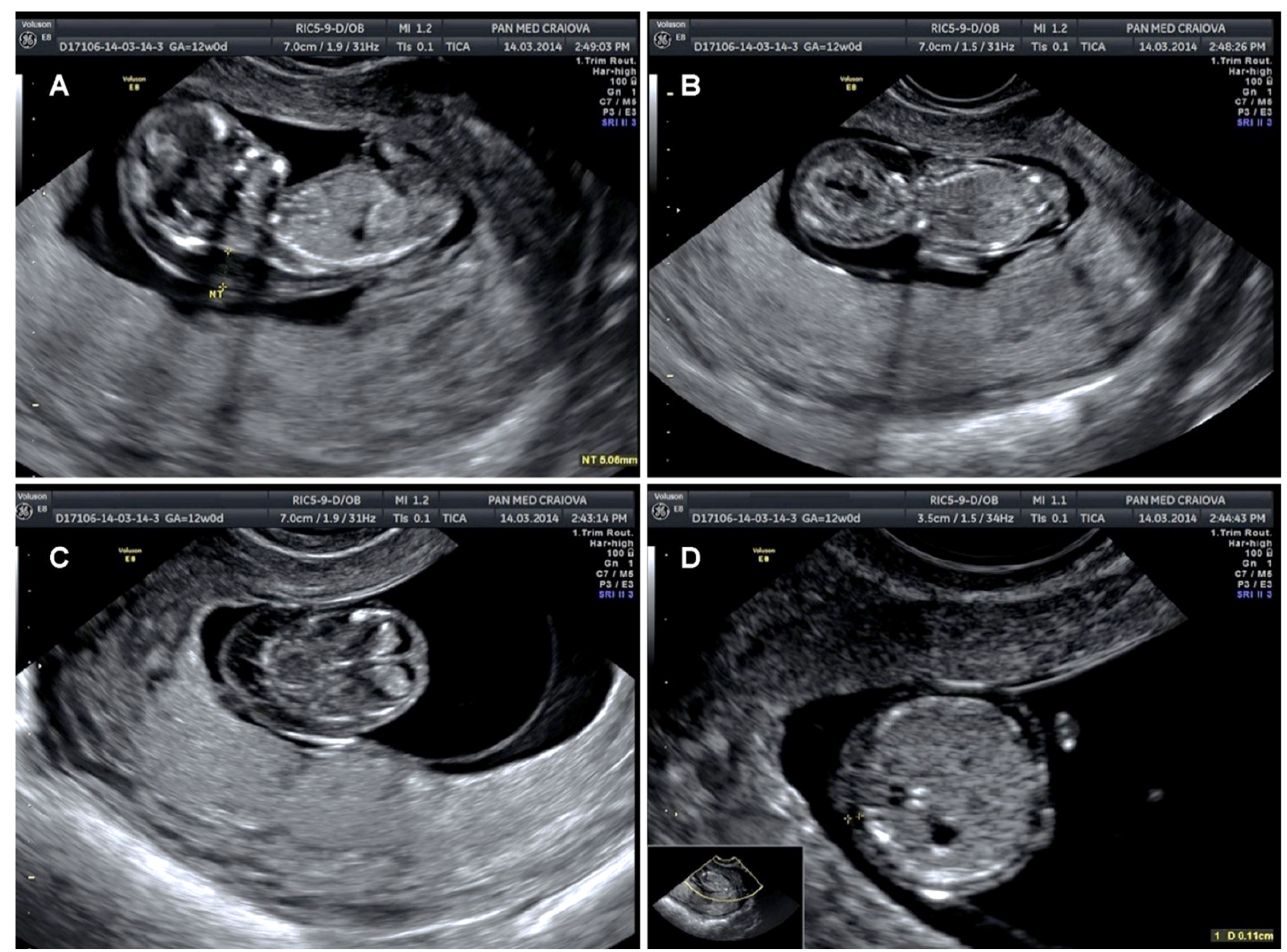

Figure 1 - Ultrasound images on the first fetus with cystic hygroma: (A) Sagittal view, NT 5.06 mm; (B) Frontal view

- CH can be observed, predominantly developed on the left part of the neck; (C) Head, transversal section - detail of multi thin-septated CH, especially on left side; (D) Abdominal transversal section - the subcutaneous edema can be observed (1.1 mm), especially affecting the anterior wall. CH: Cystic hygroma; NT: Nuchal translucency.

The diagnostic of $\mathrm{CH}$ was established and the patient was informed about the very poor fetal prognostic of this abnormality.

The patient was advised to undergo genetic investigation and she agreed for chorionic villus sampling (CVS). The karyotype was 46XX, but an increase in length of heterochromatin on the long arm of chromosome $1(1 \mathrm{qh}+)$ (Figure 2, A and B) was detected in all metaphases.

Although this karyotype was considered "normal" and "safe", the patient decided for a TOP.

One month later, she returned for her own and for her husband karyotypes. The chromosome analysis from mother peripheral blood showed a heteromorphic variant of chromosome $1(1 \mathrm{qh}+)$, and additionally other two chromosomal variants: an increase in length of the satellites on the short arm of chromosomes 14 and $21-46 \mathrm{XX}$, $1 \mathrm{qh}+14 \mathrm{ps}+, 21 \mathrm{ps}+($ Figure 2, A and B).

The patient, a university graduate, had no mention of such abnormality in her family or in the partner's family.
The father's karyotype was normal - 46XY.

Despite the medical counseling on the very low risk for another, future, $\mathrm{CH}$, especially in cases with "normal" karyotype and without an indicative familial history, the patient decided not to have another pregnancy.

However, after five years, she returned with a new immunological positive pregnancy test, at six weeks of amenorrhea.

US examination revealed a normal gestational sac (16 $\mathrm{mm}$, corresponding to six weeks and two days of amenorrhea), with an embryo having cardiac activity (171 bpm). Again, the history, clinical and laboratory investigations showed no abnormality.

At around 12 weeks of pregnancy, at the first trimester screening, the US revealed a fetus $(C R L 5.82 \mathrm{~cm}$, corresponding to 12 weeks and two days of amenorrhea) with a large septated $\mathrm{CH}$, covering almost all back side of the fetus, mainly around the neck (NT $7.78 \mathrm{~mm}$ ). The fetus showed, also, subcutaneous edema, especially 
involving the anterior thoracic and abdominal wall $(1.3 \mathrm{~mm})$ (Figure 3, A-F).

The patient asked for immediately pregnancy interruption. TOP was performed by uterine aspiration.

The genetic analysis of the tissue sample from the aspirative product revealed an extremely rare aspect a 69XXX triploidy (Figure 4).

\section{ㅁ Discussions}

The incidence of the fetal $\mathrm{CH}$ has been reported to be around $0.6 \%$ for the fetuses between weeks 11 and 14 of pregnancy [10] and one case per 6000-16 000 live births $[11,12]$. They consist in a single or multiloculated asymmetric thin-walled cavities, filled with clear or turbid fluid, more frequently situated at the neck level $(>75 \%)$ [1] - especially on left side [13] and mainly in the posterior triangle [3]. Ten to twenty percent of the tumors occur in axilla [14] and, more infrequently, in mediastinum [15], groin, scrotum [16], retroperitoneum [17], abdominal viscera [3], pelvis [18] or on the chest wall [19]. There is a male predominance - from a slight general one (59\%) $[13,20]$ to a five times ratio, for the groin [21].

$\mathrm{CH}$ is the result of an aberrant development of the lymphatic system, process which is complete in the first two months of pregnancy [22]. These tumors are thought to arise from the failure of the lymphatics to connect to the venous system [2]. CHs can be also the result of the abnormal budding of the lymphatic tissue or of the persistence of isolated lymphatic rests, which retain their embryonic potential, become canalized and continue to secret lymph, generating cystic structures $[2,12]$.

Most of the fetal CHs are associated with chromosomal

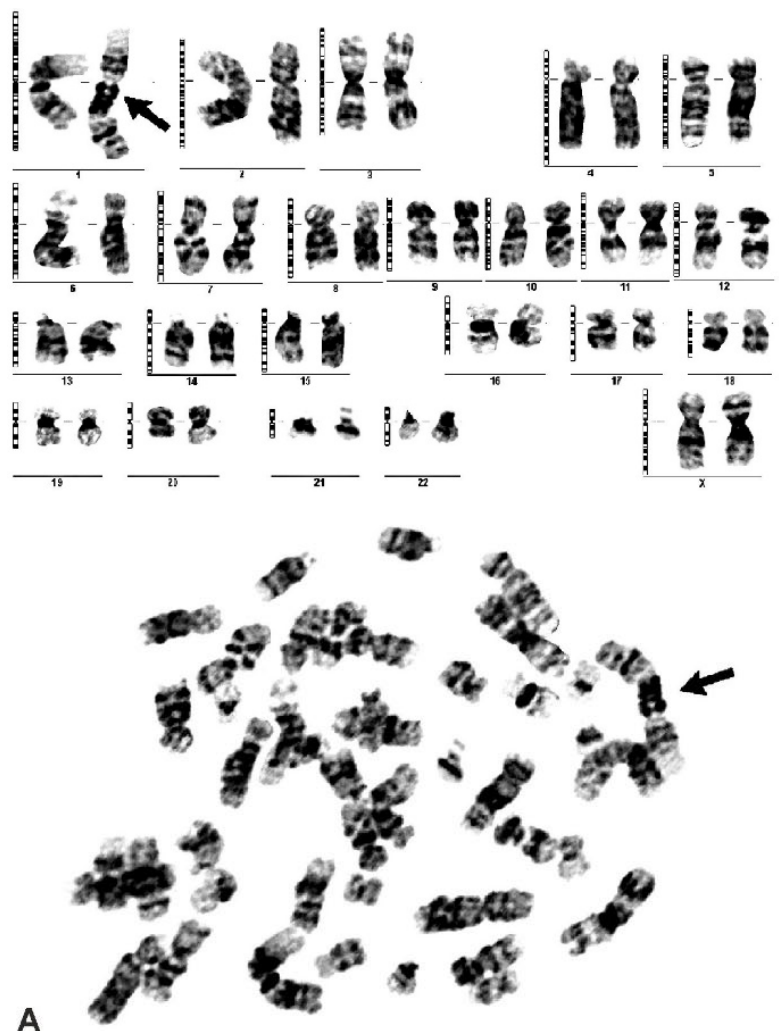

abnormalities (between 40\% and 75\%) [4, 23]. Non-septated $\mathrm{CHs}$ are more frequently observed $(61.4 \%)$ and they are predominantly associated with trisomy 21 (Down syndrome) and cardiac malformations [23]. Septated lesions are more often characterized by Turner's syndrome $(45, \mathrm{XO})$ and have an even poorer prognosis [23-25]. For this reason, when a $\mathrm{CH}$ is found, CVS or amniocentesis are mandatory. The examination of the fetal free deoxyribonucleic acid (DNA) from maternal blood is easier, safer for the fetus and earlier feasible, with a very high accuracy for chromosomal abnormalities more frequently associated with $\mathrm{CH}$. However, in many countries (Romania included), it has no legal diagnostic value.

Somehow, contrary with the majority of reported $\mathrm{CH}$, both $\mathrm{CHs}$ detailed by us, were severe septated forms, both with very particular karyotypes: the first, considered "normal", showing an inherited polymorphism of chromosome 1 (1qh+) and the other with 69XXX triploidy.

Although $\mathrm{CH}$ was long time treated as a non-inherited disease, presently, it is considered that, in the presence of "normal" karyotypes, familial occurrence has an autosomal recessive transmission [5-7, 9]. This hypothesis was not applicable in our case, since the two $\mathrm{CHs}$ had distinct karyotypes. We concluded that their successive occurrence was a pure unfortunate incident. However, $\mathrm{CHs}$ with normal karyotype can be caused by viral infections (especially with parvoviruses) [26], syphilis [27], maternal alcohol abuse during pregnancy [28] or maternal diabetes mellitus [27]. Usually, nevertheless, the etiology remains unknown [27]. It is also the case for our first reported episode of $\mathrm{CH}$, as none of the above-mentioned conditions could have been identified in the patient.
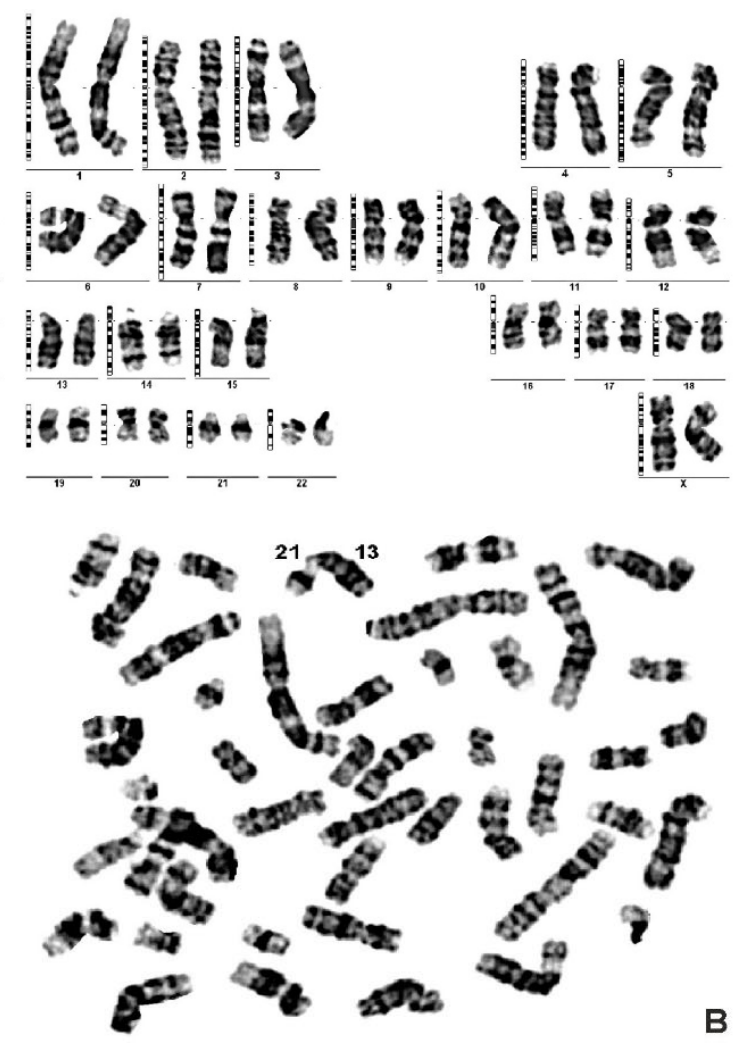

Figure 2 - The karyotypes of the first fetus with cystic hygroma (A) and of the mother $(B):(A)$ An increase in length of heterochromatin on the long arm of chromosome 1-46XX,1qh+; (B) A heteromorphic variant of chromosome 1 (1qh+), and additionally other two chromosomal polymorphisms of the satellites on the short arm of chromosomes 14 and $21-$ $46 X X, 1 q h+, 14 p s+, 21 p s+$. 

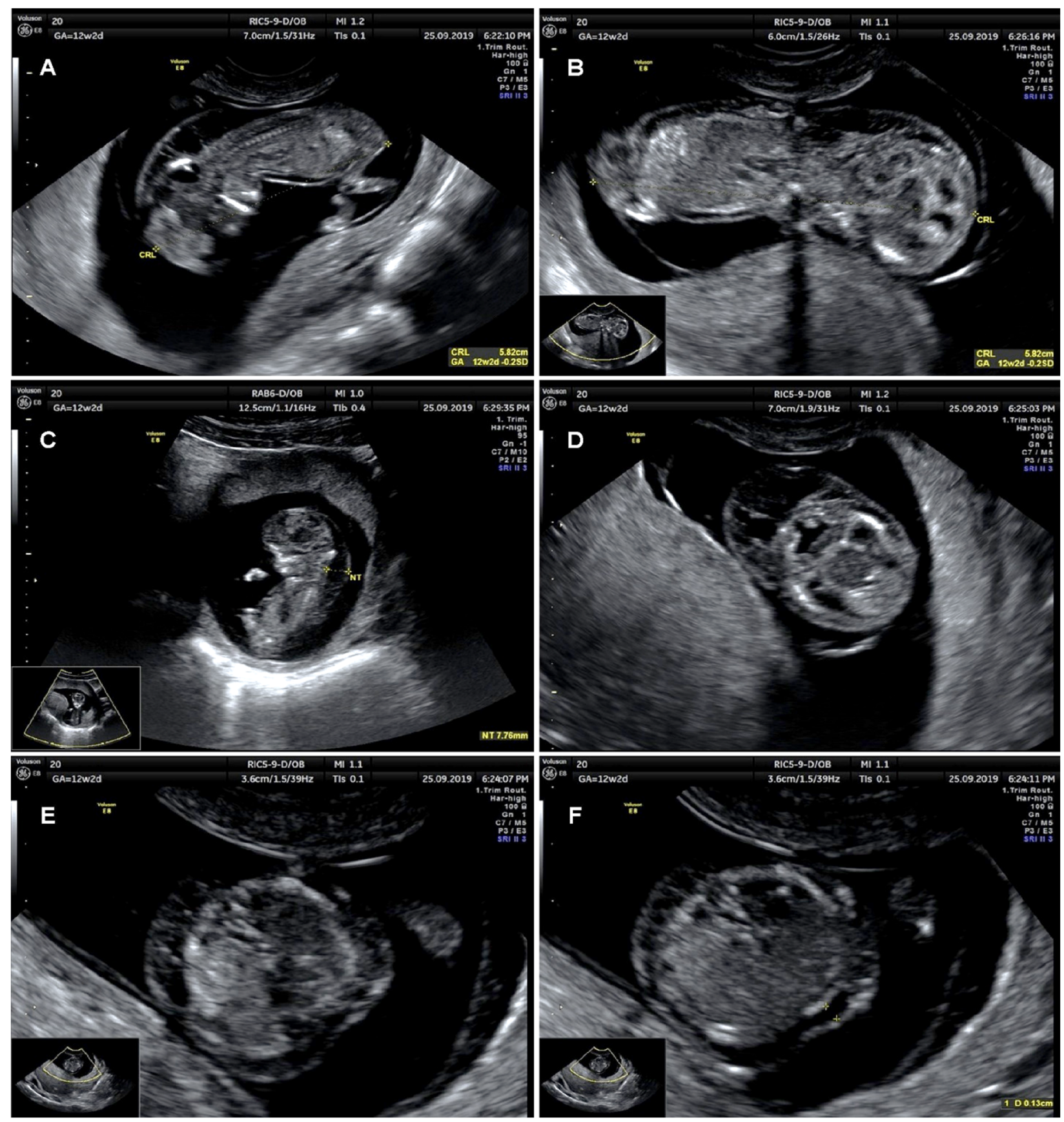

Figure 3 - Ultrasound images on the second fetus with cystic hygroma: (A) Sagittal views - the large septated CH, covering almost the whole back of the fetus, with a significant subcutaneous edema of the anterior body wall, can be seen; (B) Frontal view - CH is predominantly developed around the neck; (C) Sagittal view, NT $7.78 \mathrm{~mm}$; (D) Head, transversal section - detail of multi thin-septated $\mathrm{CH} ;(\mathrm{E}$ and $\mathrm{F})$ Thoracic and abdominal transversal sections - the subcutaneous edema (1.3 mm), especially over the anterior wall, can be observed. CH: Cystic hygroma; NT: Nuchal translucency.

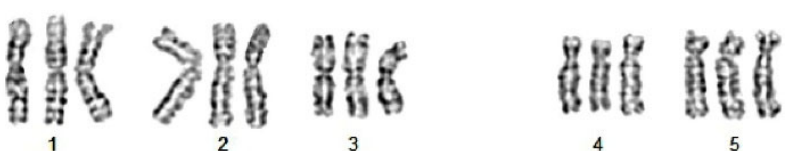

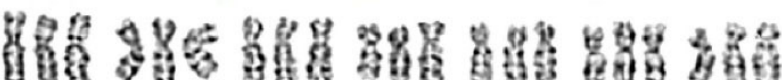
$\begin{array}{lllllll}6 & 7 & 8 & 9 & 10 & 11 & 12\end{array}$

\begin{tabular}{|c|c|c|c|c|}
\hline 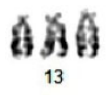 & $\underset{14}{19}$ & 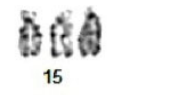 & $\begin{array}{c}65 \\
616\end{array}$ & $\begin{array}{c}40 \\
50 \\
17\end{array}$ \\
\hline 68 & $88 t$ & हैंकी & B. 8.8 & \\
\hline
\end{tabular}

Figure 4 - The karyotypes of the second fetus with cystic hygroma - 69XXX triploidy (GTC banding).
The prognosis of fetal $\mathrm{CH}$ remains very poor: around $90 \%$ of the fetuses are dying before birth $[4,23], 2 \%$ will die in the neonatal period or will maintain abnormal karyotype and/or other malformations [29], with a mortality rate in the first year of around $12 \%$ [30]. Only $8 \%$ of them will be in good health [4, 23, 29]. Sixty percent of CHs evolve to $\mathrm{HF}$, with a very bad prognosis [4]. When this lethal aspect occurs, the cystic lesion associates one or several other abnormalities, such as: ascites, uni- or bilateral pleural or pericardial effusions and subcutaneous edema (greater than $5 \mathrm{~mm}$ thick) [3, 4]. Therefore, if a CH is diagnosed, a carefully US search for all these negative aspects should be done [3].

Both HF reported by us, associated $\mathrm{CH}$ with 
subcutaneous edema, especially located on the anterior body wall.

Only a small percent of CHs spontaneously disappear before 20 weeks, but this does not exclude chromosomal abnormalities and/or severe fetal malformations [4] and reappearance is also possible [29].

Chromosomal aneuploidy [4], septated CHs [23] and the lack of spontaneous resolution [4] suggest a poor prognosis [4, 23]; however, the absence of these factors is not a guaranty for a favorable development [4]. Ascites and/or pleural fluid (especially bilateral), oligohydramnios or polyhydramnios, are factors for an even worse prognosis [3].

The secondary constriction of chromosome 1 (1qh+), as showed by the inherited karyotype of the first $\mathrm{CH}$ reported here, is considered a "normal" and "healthy" polymorphism of chromosome 1 [31]. This general appreciation is concordant with the fact that our patient was in a very good health, with a high intelligence level (university graduate).

However, there are some authors that report a lower fertility of women with such polymorphisms [32]. This was, also, not valuable in our case, who already had a healthy boy and another two voluntary TOP, with the previous husband, before the first $\mathrm{CH}$.

Nevertheless, such a "healthy" 46XX(1qh+) karyotype did not exclude the occurrence, in our case, of a severe form of septated $\mathrm{CH}$ with $\mathrm{HF}$.

The karyotype of the second fetus with septated $\mathrm{CH}$ is absolutely unique, the present case being the first reported having a 69XXX triploidy. This abnormality is frequently associated with partial hydatidiform mole [33] and is life incompatible [34]. However, since the second $\mathrm{CH}$ had a significantly more severe aspect compared with the first one, it can be speculated that the 69XXX triploidy could be the cause for the second abnormal fetus (Figures 1 and 3).

There are very few recurrent $\mathrm{CHs}$ with different karyotypes described in the literature, [8], but our case is the first one reported recurrent $\mathrm{CH}$ showing such particular genetic features.

\section{ㅁ Conclusions}

We report, on our knowledge, the first case of a recurrent $\mathrm{CH}$, each of the subsequent embryos with a such karyotype: inherited 46XX (1qh+) and 69XXX. The etiology of the first fetal $\mathrm{CH}$ remains unknown and the large secondary constriction of chromosome 1 (1qh+) was not a cause for the first $\mathrm{CH}$ appearance. Furthermore, this "particular" genetic aspect did not associate with any maternal abnormality and behaved itself as a "normal" karyotype, fortuitously co-existing with a $\mathrm{CH}$. The 69XXX triploidy, in the second episode, could be a cause of this disease or, even more, for its higher severity. Neither the CHs' appearance, nor their recurrence seemed to be family-linked, the two $\mathrm{CHs}$ having distinct genetic profiles. Once $\mathrm{CH}$ is diagnosed, a careful US examination is compulsory for the determination of subcutaneous edema, ascites, pleural and pericardial effusions and cardiac or renal abnormalities and the patient should be advised on the very poor fetal outcome. CVS or amniocentesis are mandatory, because a defective karyotype is a supplementary bad prediction factor; however, a "normal" karyotype does not significantly improve the fetal prognosis.

\section{Conflict of interests}

The authors declare that they have no conflict of interests.

\section{Acknowledgments}

The patient agreed for publication of all her private data.

The study was supported by PanMed S.R.L. Grant 119.1/26.02.2019.

The authors are very grateful to the Department of Genetics, University of Medicine and Pharmacy of Craiova and to the Dr. Cristina Gug Laboratory of Genetics, Timişoara, Romania.

\section{Authors' contribution}

Oana Sorina Tica and Cristina Gug equally contributed to this paper.

\section{References}

[1] Burezq H, Williams B, Chitte SA. Management of cystic hygromas: 30 year experience. J Craniofac Surg, 2006, 17(4):815-818. https://doi.org/10.1097/00001665-20060700 0-00041 PMID: 16877942

[2] Chervenak FA, Isaacson G, Blakemore KJ, Breg WR Hobbins JC, Berkowitz RL, Tortora M, Mayden K, Mahoney MJ. Fetal cystic hygroma. Cause and natural history. N Engl J Med, 1983, 309(14):822-825. https://doi.org/10.1056/NEJM1983 10063091403 PMID: 6888468

[3] Song TB, Kim CH, Kim SM, Kim YH, Byun JS, Kim EK. Fetal axillary cystic hygroma detected by prenatal ultrasonography: a case report. J Korean Med Sci, 2002, 17(3):400-402. https://doi.org/10.3346/jkms.2002.17.3.400 PMID: 12068147 PMCID: PMC3054879

[4] Bernard P, Chabaud JJ, Le Guern H, Le Bris MJ, Boog G. [Cystic hygroma of the neck. Antenatal diagnosis, prognostic factors, management. 42 cases]. J Gynecol Obstet Biol Reprod (Paris), 1991, 20(4):487-495. PMID: 1885883

[5] Rotmensch S, Celentano C, Sadan O, Liberati M, Lev D, Glezerman M. Familial occurrence of isolated nonseptated nuchal cystic hygromata in midtrimester of pregnancy. Prenat Diagn, 2004, 24(4):260-264. https://doi.org/10.1002/pd.849 PMID: 15065099

[6] Tricoire J, Sarramon MF, Rolland M, Lefort G. Familial cystic hygroma. Report of 8 cases in 3 families. Genet Couns, 1993, 4(4):265-269. PMID: 8110412

[7] Baxi L, Brown S, Desai K, Thaker H. Recurrent cystic hygroma with hydrops. Fetal Diagn Ther, 2009, 25(1):127-129. https:// doi.org/10.1159/000207553 PMID: 19276638

[8] Watson WJ, Thorp JM Jr, Seeds JW. Familial cystic hygroma with normal karyotype. Prenat Diagn, 1990, 10(1):37-40. https://doi.org/10.1002/pd.1970100107 PMID: 2179939

[9] Teague KE, Eggleston MK, Muffley PE, Gherman RB. Recurrent fetal cystic hygroma with normal chromosomes: case report and review of the literature. J Matern Fetal Med, 2000, 9(6):366-369. https://doi.org/10.1002/1520-6661(2000 11/12)9:6<366::AID-MFM1010>3.0.CO;2-E PMID: 11243297

[10] Kharrat R, Yamamoto M, Roume J, Couderc S, Vialard F, Hillion $Y$, Ville $Y$. Karyotype and outcome of fetuses diagnosed with cystic hygroma in the first trimester in relation to nuchal translucency thickness. Prenat Diagn, 2006, 26(4):369-372. https://doi.org/10.1002/pd.1423 PMID: 16566042

[11] Sannoh S, Quezada E, Merer DM, Moscatello A, Golombek SG. Cystic hygroma and potential airway obstruction in a newborn: a case report and review of the literature. Cases J, 2009 2(1):48. https://doi.org/10.1186/1757-1626-2-48 PMID: 19144130 PMCID: PMC2631536

[12] Patel VA, Cleveland C, Carr MM. Lymphatic malformations (cystic hygroma) clinical presentation. Medscape, 2020. https:// emedicine.medscape.com/article/994055-clinical 
[13] Ozen IO, Moralioglu S, Karabulut R, Demirogullari B, Sonmez K, Turkyilmaz Z, Basaklar AC, Kale N. Surgical treatment of cervicofacial cystic hygromas in children. ORL J Otorhinolaryngol Relat Spec, 2005, 67(6):331-334. https://doi.org/10. 1159/000090043 PMID: 16327272

[14] Zanotti SD, LaRusso S, Coulson C. Prenatal sonographic diagnosis of axillary cystic lymphangiomas. J Clin Ultrasound 2001, 29(2):112-115. https://doi.org/10.1002/1097-0096(2001 02)29:2<112::AID-JCU1009>3.0.CO;2-Q PMID: 11425089

[15] Ratan J, Bhatnagar V, Mitra DK. Mediastinal cystic hygroma in infancy and childhood. Pediatr Surg Int, 1992, 7(5):380381. https://doi.org/10.1007/BF00176599

[16] Gueukdjian SA. Cystic hygroma of the groin and scrotum. $\mathrm{Br}$ J Urol, 1956, 28(3):279-282. https://doi.org/10.1111/j.14 64-410x.1956.tb04771.x PMID: 13364268

[17] Ozdemir H, Kocakoc E, Bozgeyik Z, Cobanoglu B. Recurrent retroperitoneal cystic lymphangioma. Yonsei Med J, 2005, 46(5):715-718. https://doi.org/10.3349/ymj.2005.46.5.715 PMID: 16259073 PMCID: PMC2810581

[18] Sheth S, Nussbaum AR, Hutchins GM, Sanders RC. Cystic hygromas in children: sonographic-pathologic correlation. Radiology, 1987, 162(3):821-824. https://doi.org/10.1148/ radiology.162.3.3544038 PMID: 3544038

[19] Arora A, Narula MK, Sonkar P, Chadha R. Letter to Editor: Cystic hygroma of chest wall. Indian J Radiol Imaging, 2003, 13(1):120-121. https://www.ijri.org/text.asp?2003/13/1/120/28 644

[20] Uba AF, Chirdan LB. Management of cystic lymphangioma in children: experience in Jos, Nigeria. Pediatr Surg Int, 2006 22(4):353-356. https://doi.org/10.1007/s00383-006-1642-7 PMID: 16447072

[21] Yuh WT, Buehver LS, Kao SC, Robinson RA, Dolan KD, Phillips JJ. Magnetic resonance imaging of pediatric head and neck cystic hygromas. Ann Otol Rhinol Laryngol, 1991, 100(9 Pt 1):732-742. https://doi.org/10.1177/00034894911 0000910 PMID: 1952667

[22] Joseph AE, Donaldson JS, Reynolds M. Neck and thorax venous aneurysm: association with cystic hygroma. Radiology, 1989, 170(1 Pt 1):109-112. https://doi.org/10.1148/radiology. 170.1.2642338 PMID: 2642338

[23] Gedikbasi A, Gul A, Sargin A, Ceylan Y. Cystic hygroma and lymphangioma: associated findings, perinatal outcome and prognostic factors in live-born infants. Arch Gynecol Obstet, 2007, 276(5):491-498. https://doi.org/10.1007/s00404-0070364-y PMID: 17429667

[24] Brumfield CG, Wenstrom KD, Davis RO, Owen J, Cosper P. Second-trimester cystic hygroma: prognosis of septated and nonseptated lesions. Obstet Gynecol, 1996, 88(6):979-982. https://doi.org/10.1016/s0029-7844(96)00358-4 PMID: 8942838

[25] Bronshtein M, Bar-Hava I, Blumenfeld I, Bejar J, Toder V, Blumenfeld $Z$. The difference between septated and nonseptated nuchal cystic hygroma in early second trimester. Obstet Gynecol, 1993, 81(5 Pt 1):683-687. PMID: 8469454

[26] Kaiser L, Sükösd F, Veszprémi B, Arany A, Vizer M, Szabó I, Kisfaludy N, Magyar E, Pajor L. [Parvovirus B19 infection in hydrops fetalis]. Orv Hetil, 2000, 141(30):1661-1665. PMID: 10962903

[27] Rodríguez MM, Chaves F, Romaguera RL, Ferrer PL, de la Guardia C, Bruce JH. Value of autopsy in nonimmune hydrops fetalis: series of 51 stillborn fetuses. Pediatr Dev Pathol, 2002, 5(4):365-374. https://doi.org/10.1007/s10024-001-0260-6 PMID: 12016530

[28] Edwards MJ, Graham JM Jr. Posterior nuchal cystic hygroma. Clin Perinatol, 1990, 17(3):611-640. PMID: 2225690

[29] Descamps $P$, Jourdain O, Paillet $C$, Toutain A, Guichet $A$, Pourcelot D, Gold F, Castiel M, Body G. Etiology, prognosis and management of nuchal cystic hygroma: 25 new cases and literature review. Eur J Obstet Gynecol Reprod Biol, 1997, 71(1):3-10. https://doi.org/10.1016/S0301-2115(96)02590-0 PMID: 9031953

[30] Fisher R, Partington A, Dykes E. Cystic hygroma: comparison between prenatal and postnatal diagnosis. J Pediatr Surg, 1996, 31(4):473-476. https://doi.org/10.1016/s0022-3468(96) 90477-7 PMID: 8801294

[31] Hong Y, Zhou YW, Tao J, Wang SX, Zhao XM. Do polymorphic variants of chromosomes affect the outcome of in vitro fertilization and embryo transfer treatment? Hum Reprod, 2011, 26(4):933-940. https://doi.org/10.1093/humrep/deq333 PMID: 21266453 PMCID: PMC3057751

[32] Mierla D, Stoian V. Chromosomal polymorphisms involved in reproductive failure in the Romanian population. Balkan J Med Genet, 2012, 15(2):23-28. https://doi.org/10.2478/bjmg -2013-0003 PMID: 24052728 PMCID: PMC3776661

[33] Tica AA, Tica OS, Georgescu CV, Mixich F, Tica VJ, Berceanu S, Ebanca E, Patrascu A, Simionescu C. Recurrent partial hydatidiform mole, with a first twin pregnancy, after treatment with clomiphene citrate. Gynecol Endocrinol, 2009, 25(8): 514-519. https://doi.org/10.1080/09513590902972125 PMID: 19499414

[34] Gainer JA. Chapter 148: Triploidy. In: Copel JA, D’Alton ME, Feltovich $\mathrm{H}$, Gratacós E, Krakow D, Odibo AO, Platt LD, Tutschek B (eds). Obstetric imaging: fetal diagnosis and care. $2^{\text {nd }}$ edition, Elsevier, Philadelphia, 2017, 598-601.

\section{Corresponding authors}

Andrei Adrian Tica, Professor, MD, PhD, Department of Pharmacology, University of Medicine and Pharmacy of Craiova, 2 Petru Rareş Street, 200349 Craiova, Dolj County, Romania; Phone +40745-035 638, e-mail: ticaandrei2002@yahoo.com

Irina Tica, Associate Professor, MD, PhD, Department of Internal Medicine, Faculty of Medicine, Ovidius University of Constanţa, Campus, 1 University Street, 900470 Constanţa, Constanţa County, Romania; Phone +40724-864 834, e-mail: irinatica@gmail.com 